\title{
Methods to reduce prescribing errors in elderly patients with multimorbidity
}

\author{
This article was published in the following Dove Press journal: \\ Clinical Interventions in Aging \\ 23 June 2016 \\ Number of times this article has been viewed
}

\author{
Amanda H Lavan \\ Paul F Gallagher \\ Denis O'Mahony \\ Department of Geriatric Medicine, \\ Cork University Hospital, University \\ College Cork, Cork, Ireland
}

\begin{abstract}
The global population of multimorbid older people is growing steadily. Multimorbidity is the principal cause of complex polypharmacy, which in turn is the prime risk factor for inappropriate prescribing and adverse drug reactions and events. Those who prescribe for older frailer multimorbid people are particularly prone to committing prescribing errors of various kinds. The causes of prescribing errors in this patient population are multifaceted and complex, including prescribers' lack of knowledge of aging physiology, geriatric medicine, and geriatric pharmacotherapy, overprescribing that frequently leads to major polypharmacy, inappropriate prescribing, and inappropriate drug omission. This review examines the various ways of minimizing prescribing errors in multimorbid older people. The role of education in physician prescribers and clinical pharmacists, the use of implicit and explicit prescribing criteria designed to improve medication appropriateness in older people, and the application of information and communication-technology systems to minimize errors are discussed in detail. Although evidence to support any single intervention to prevent prescribing errors in multimorbid elderly people is inconclusive or lacking, published data support focused prescriber education in geriatric pharmacotherapy, routine application of STOPP/START (screening tool of older people's prescriptions/screening tool to alert to right treatment) criteria for potentially inappropriate prescribing, electronic prescribing, and close liaison between clinical pharmacists and physicians in relation to structured medication review and reconciliation. Carrying out a structured medication review aimed at optimizing pharmacotherapy in this vulnerable patient population presents a major challenge. Another challenge is to design, build, validate, and test by clinical trials suitably versatile and efficient software engines that can reliably and swiftly perform complex medication reviews in older multimorbid people. The European Union-funded SENATOR and OPERAM clinical trials commencing in 2016 will examine the impact of customized software engines in reducing medication-related morbidity, avoidable excess cost, and rehospitalization in older multimorbid people.
\end{abstract}

Keywords: prescribing errors, multimorbidity, aged

\section{Introduction}

According to the UN, an "older person" is 60 years or older, with persons aged $\geq 80$ years being referred to as the "oldest old". ${ }^{1}$ The global population is aging, with the number of people aged over 65 years expected to reach 71 million by 2030, compared to 35 million in 2000. By 2050, the global average life expectancy is predicted to have increased by 10 years compared to $2000,{ }^{2}$ and by 2080 , the over- 80 population will likely double.

With the predicted global demographic shift, the prevalence of multimorbidity, defined as two or more concurrent chronic medical conditions, will rise. At present, $81.5 \%$ of people aged over 85 years experience multimorbidity, compared to $62 \%$ of those aged $65-74$ years and $50 \%$ of those under 65 years. ${ }^{3}$ Multimorbidity is three
Correspondence: Denis O'Mahony Department of Geriatric Medicine, Cork University Hospital, Wilton,

Cork TI2DC4A, Ireland

Tel +353 2l 4922396

Fax +353 2I 4922829

Email denis.omahony@ucc.ie (c) (7) (5) 2016 Lavan et al. This work is published and licensed by Dove Medical Press Limited. The full terms of this license are available at https://www.dovepress.com/terms.php

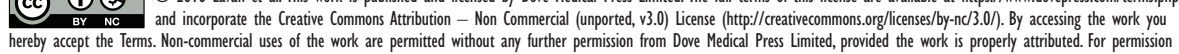
for commercial use of this work, please see paragraphs 4.2 and 5 of our Terms (https://www.dovepress.com/terms.php). 
times more prevalent in those aged 85 years compared to those aged 70 years. ${ }^{4}$ Multimorbid patients are prescribed more medications, which increases their risk of inappropriate prescribing (IP), ${ }^{5}$ drug-drug interactions, ${ }^{6}$ drug-disease interactions, adverse drug events (ADEs), ${ }^{7}$ and medication errors ${ }^{8}$ all of which are intimately linked. Problems associated with all aspects of prescribing will increase amid an aging multimorbid population unless they are clearly identified and comprehensively addressed. This review examines prescribing errors in the multimorbid older population, and proposes potentially feasible strategies to address them.

\section{Definition}

In the literature, "medication error" and "prescribing error" are often used interchangeably, making study comparisons difficult. Distinguishing medication errors from prescribing errors is important, as different types of errors are influenced by different factors, result in different outcomes, and require different actions. Ferner and Aronson defined a medication error as "a failure in the treatment process that leads to, or has the potential to lead to, harm to the patient". ${ }^{9}$ However, this definition of medication error encompasses prescribing errors, administration errors, and dispensing errors.

In 2000, through a Delphi consensus panel of doctors, surgeons, pharmacists, nurses, and risk managers, Dean et al proposed that significant prescription errors happen when without intention, the probability of timely and effective treatment is reduced and/or the risk of drug-related adversity is heightened. ${ }^{10}$

Prescribing errors can be further characterized into groups, as demonstrated in Table $1 .{ }^{11}$

\section{Incidence and prevalence of prescribing errors}

Prescribing errors occur in all health care settings. In hospitalized patients, they are more common in adults than in children (median prevalence 18\% [interquartile range $7 \%-25 \%]$ versus median $4 \%[2 \%-17 \%]) .{ }^{12}$ They occur on average 8.8 times per 100 medication orders, and are $70 \%$

Table I Classification of prescribing errors

\begin{tabular}{ll}
\hline Omission error & Deletion of a drug previously used \\
Commission error & Addition of a drug not previously used \\
Dosing error & Incorrect dose \\
Frequency error & $\begin{array}{l}\text { Incorrect frequency } \\
\text { Incorrect form }\end{array}$ \\
Form error & A drug from one class substituted for another \\
Substitution error & drug from the same class not previously used \\
Duplication error & Two drugs from the same class being prescribed \\
\hline
\end{tabular}

more likely to occur at the time of hospital admission. ${ }^{13}$ One UK study looked at prescribing errors in primary care, and found that both patients aged $\geq 65$ years and under 15 years were at highest risk. ${ }^{14}$ Of these patients, one in eight experienced a prescribing error or monitoring error. Although the great majority of these errors were mild to moderate, one in 550 was deemed clinically serious. ${ }^{14}$

Care-home residents, the majority of whom have multimorbidity, are at a particularly high risk of prescribing errors. A recent large-scale US study reported that $93 \%$ of nursing-home residents had three or more conditions and on average were prescribed eight medications daily. ${ }^{15}$ Another study found that medication errors occurred in two-thirds of residents, and prescribing errors, as defined by Dean et al, occurred in $39.1 \%{ }^{16}$ The most common types of prescribing errors seen in this cohort were "incomplete information" (no route or dose specified) at 37.9\%, "unnecessary drug" at $23.5 \%$, "dose error" at $14.4 \%$, and "omission errors" at $11.8 \%{ }^{16}$ Notably, care-home residents are at the highest risk of prescribing errors, as well as administration and dispensing error, when they move between primary and secondary care. ${ }^{17}$ This is concerning for the future in view of the growing populations of nursing-home residents in developed countries. For instance, $7 \%$ of people aged $\geq 65$ years in Ireland ${ }^{18}$ and $3 \%$ of similarly aged people in the US live in nursing homes. ${ }^{19,20}$ It is highly probable that prescribing errors will increase in this growing population of frail older people unless improved reliable systems for detection and correction of medication errors are put in place.

\section{Causes of prescribing errors}

Developing strategies to reduce prescribing errors in older adults is dependent on identifying the key causative factors that lead to these errors. One Dutch study found that prescriber and drug characteristics were the factors most strongly associated with prescribing errors. ${ }^{21}$ Several other factors are also associated with prescribing errors in older people. Dean et al have divided these into categories of individual and team factors, patient-related factors, work-environment factors, and task-related factors. ${ }^{22}$ Details of these prescribing-error risk factors are illustrated in Figure 1.

Doctors often work in stressful and busy environments, with frequent distractions that may impinge on thought processes while prescribing. Junior doctors, who do the majority of prescribing within hospitals, frequently rotate from one specialist department to another, needing to adapt quickly to a new cluster of commonly prescribed drugs within that specialty. Because of various other demands on 


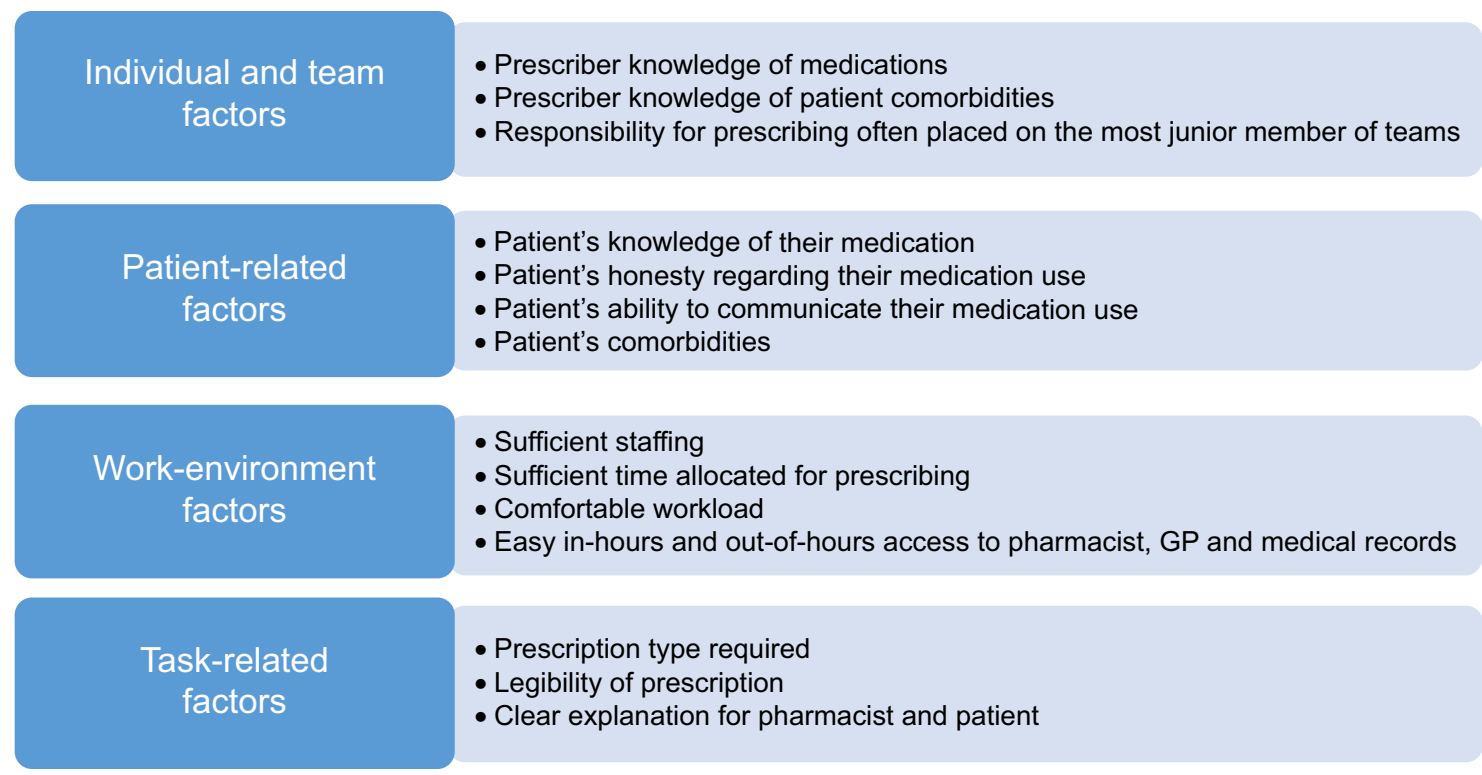

Figure I Classification of factors that predispose to prescribing errors.

their attention in their day-to-day work, junior trainees may depend on nurses and pharmacists to identify prescribing errors, particularly in nonelectronic prescribing systems.

Older persons who become acutely ill may be assessed by general practitioners on call or admitted to hospital by doctors who do not know their clinical details outside normal working hours. Alongside this, access to older persons' community pharmacist records, hospital medical records, and primary care records may be suboptimal. Consequently, there is an increased risk of prescribing errors occurring, and such errors may not be identified and addressed for some considerable time after hospital admission, by which time an adverse clinical consequence may have occurred.

Prescribing errors may originate with older persons themselves when discussing their medications, particularly frailer older multimorbid patients who have complex daily medications routines when they are acutely unwell. Such conditions as dementia, acute stroke, or delirium are common in older people, and often impede their capacity to communicate clearly. In such circumstances, medication reconciliation (MR), the process of compiling a patient's detailed medication list, can be difficult or sometimes impossible if the attending hospital physician does not have access to the patient's primary care clinical records. Although GPs know which drugs are being prescribed to their older multimorbid patients, not uncommonly they are unaware of the full list of drugs that older patients actually take. Frank et al reported that approximately $40 \%$ of older patients take drugs that their GP is unaware of and that $5 \%$ of patients do not take medications listed on their primary care prescription record. ${ }^{23}$ It is not surprising that prescribing errors happen most frequently at the time of transition of care, particularly on admission to hospital, when older patients have their medications prescribed by a doctor who is usually unknown to them. ${ }^{24}$

\section{Age-related pharmacokinetics, pharmacodynamics, and prescribing errors}

Everybody who prescribes for older people needs to be aware of the important physiological changes that occur with aging that affect drug pharmacokinetics (absorption, distribution, metabolism, and excretion) and pharmacodynamics (the effect a drug has on the body). These changes predispose older people to adverse outcomes arising from prescribing errors. Figure 2 summarizes the key pharmacokinetic changes associated with old age.

Absorption may be affected by drugs that are commonly prescribed in older people, such as anticholinergic drugs, which reduce the production of saliva, and proton-pump inhibitors, which reduce gastric acid secretion. With advancing age, muscle mass declines, with a resultant proportional increase in total body fat. These changes affect the volume of distribution of both lipophilic drugs, such as benzodiazepines, and hydrophilic drugs, such as lithium. Consequently, in older adults lipophilic drugs have a larger volume of distribution, which results in a longer half-life, a tendency to drug accumulation, and a lower threshold for adverse 


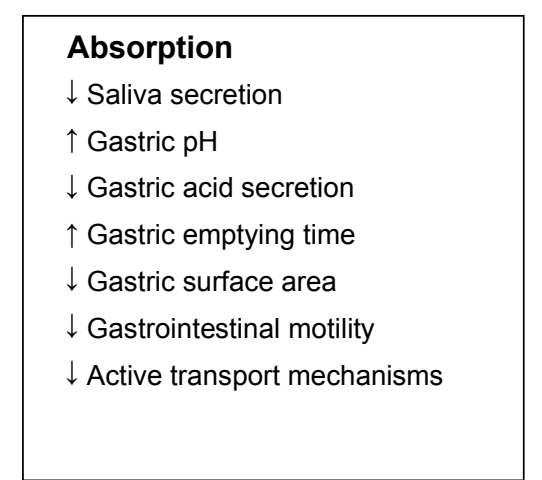

\section{Metabolic \\ $\downarrow$ Microsomal hepatic oxidation \\ $\downarrow$ Clearance \\ $\uparrow$ Steady-state levels \\ $\uparrow$ Half-lives \\ $\uparrow$ Levels of active metabolites \\ $\downarrow$ First-pass metabolism}

\section{Distribution \\ $\downarrow$ Cardiac output \\ $\uparrow$ Peripheral vascular resistance \\ $\downarrow$ Hepatic blood flow \\ $\downarrow$ Renal blood flow \\ $\downarrow$ Body water content \\ $\uparrow$ Adipose tissue \\ $\downarrow$ Serum albumin \\ $\uparrow$ Distribution for lipid-soluble drugs \\ $\downarrow$ Distribution for water-soluble drugs}

\section{Excretion}

$\downarrow$ Renal perfusion

$\downarrow$ Renal size

$\downarrow$ Glomerular filtration rate

$\downarrow$ Tubular secretion

$\downarrow$ Tubular reabsorption excretion

Figure 2 Age-related changes in pharmacokinetics.

drug reactions (ADRs). When the volume of distribution of hydrophilic drugs is reduced, the risk of toxicity is greater if doses are not adjusted, particularly where there is coexisting renal impairment.

Chronic illness and malnutrition can lower serum albumin levels, which in turn can affect highly protein-bound drugs, such as ibuprofen and phenytoin. This results in an increased concentration of circulating free drug and a lower threshold for adverse effects. Liver mass and perfusion declines by approximately $30 \%-40 \%$ with advancing age, ${ }^{25}$ impacting on drugs with high hepatic extraction ratio, such as warfarin. This results in a reduction in first-pass metabolism, an increase in bioavailability, and the potential for high serum drug levels.

Drug-drug interactions within the cytochrome P450 enzyme system of the liver are of particular concern in older adults on multiple medications. For example, an older person prescribed clarithromycin in tandem with warfarin can experience bleeding due to inhibition of warfarin metabolism. In other circumstances, the combination of certain drugs with similar pharmacological effects can result in significant toxicity, eg, haloperidol prescribed with amitriptyline increases the potential for major anticholinergic side effects, such as severe constipation and even delirium.

Renal size, perfusion, and function decline with aging, leading to a reduction in glomerular filtration rate (GFR). ${ }^{26}$ This affects the elimination of medications, and doses need to be adjusted accordingly. This is particularly relevant when older adults become acutely unwell, when their GFR may decline significantly, thereby increasing their risk of certain ADRs with drugs that are mainly excreted through the kidneys, eg, digoxin, lithium, aminoglycosides, and rivaroxaban. ADRs in turn often prolong admission, ${ }^{27}$ resulting in higher risk of morbidity and mortality, ${ }^{28}$ as well as greater hospital costs. ${ }^{27}$ Calculation of estimated GFR is therefore recommended for renally eliminated drugs each time a prescription is written. Serum creatinine concentration alone as an indicator of renal function may be misleading, since approximately $50 \%$ of older adults with normal creatinine have a reduced estimated GFR. ${ }^{29}$

Older multimorbid adults are more sensitive to the effects of certain commonly prescribed drugs compared to younger adults. Pathological changes to organs, differences in receptor affinities and densities, and changes in postreceptor events at a cellular level may alter pharmacodynamics. As a result of pharmacodynamic changes, older people are more sensitive to the effects of such drugs as warfarin, opioids, furosemide, neuroleptic antipsychotics, and benzodiazepines. For this reason, prescribers should initiate these drugs at the lowest possible dose and titrate slowly.

As a result of these age-related pharmacokinetic and pharmacodynamic changes, prescribing errors when they occur in older adults are more likely to have clinical consequences. Although most medication errors do not lead to ADEs, those that do cause ADEs are mostly preventable.$^{30}$ In one study of approximately 36,200 prescriptions, prescribing errors 
were found in $1.5 \%$ of cases, with about a quarter of these having the potential to cause serious harm to the patient. ${ }^{31}$ Most errors in this study related to dosing. There are multiple factors that contribute to prescribing errors; therefore, a multifaceted strategy is required to minimize them and their potentially adverse consequences.

\section{Methods to reduce prescribing errors \\ Education}

Although many nurses and pharmacists have assumed prescribing responsibilities, the majority of prescribing is still carried out by doctors. Most medical schools provide some training in prescribing to medical undergraduates; however, this training is perceived to be suboptimal by medical students and junior doctors. ${ }^{32}$ A UK prospective cross-sectional study across three universities reported that medical students were underprepared for prescribing, with weaknesses identified in clinical pharmacology/therapeutic knowledge and the practical elements of drug prescribing, such as calculating doses and writing prescriptions correctly. ${ }^{33}$ Notably, doctors in their first 2 years of postgraduate practice are twice as likely to prescribe incorrectly compared to medical consultants. ${ }^{13}$

The recent PROTECT study of prescribing performance in foundation doctors in Scotland reported that these foundation doctors made more prescribing errors than other doctors; perhaps not surprisingly, as they undertake the majority of prescribing in hospital. ${ }^{34}$ Prescribing errors occurred at a significantly higher rate in teaching hospitals $(P<0.001)$, surgical wards $(P \leq 0.001)$, or mixed medical and surgical $(P=0.008)$ wards compared to medical wards. Prescription errors were also significantly higher where there was a higher patient turnover $(P<0.001)$, a greater number of prescribed medicines $(P<0.001)$, and during the months of December and June $(P<0.001)$. The study concluded that prescribing errors in foundation doctors were multifactorial, involving work environment, team, task, individual, and patient factors. For this reason, corrective action among junior doctors needs to be multifaceted.

In 2009, a systematic review ${ }^{35}$ of prescribing-optimization interventions identified the World Health Organization's Guide to Good Prescribing ${ }^{36}$ as the only intervention tested on students that was shown to have significant improvements on prescribing. More recently, a Dutch randomized controlled trial involving 106 medical students found that students trained in the use of the STRIP (systematic tool to reduce IP) software tool alongside the deployment of STOPP/START (screening tool of older people's prescriptions/screening tool to alert to right treatment) criteria ${ }^{37}$ performed significantly better on a battery of prescribing-skill assessment tests than students who did not receive training in STRIP or STOPP/ START criteria. ${ }^{38}$ With regard to physicians' continuing medication education, interactive techniques have been shown to change physician practices and improve patient care. ${ }^{39}$

A recent metasynthesis by Cullinan et al examined the core reasons for IP in older people. ${ }^{40}$ Of 624 qualitative research papers in the literature, only seven papers were identified as relevant. Using metaethnographic methods to synthesize these seven papers, the following factors were identified as significant contributors to IP: 1) need to satisfy the patient, 2) feeling of being forced to prescribe, 3) prescribing experience prevailing over prescribing guidelines, and 4) prescribers' feelings of fear of countermanding other physicians' prescription orders. A follow-up study of hospital doctors, ${ }^{41}$ again using qualitative methodology, examined the core barriers to appropriate prescribing in older people and types of interventions likely to improve prescribing appropriateness. This study found that the key factors that influence prescribing appropriateness were environmental context and resources, knowledge, skills, social influences, and memory/attention and decision processes. The authors concluded that prescribing training and improved prescribing environment were most likely to have a positive impact of prescribing appropriateness in older people. In a follow-on randomized control trial, Cullinan et al examined the impact of a structured online geriatric prescribing-education program in junior hospital doctors. ${ }^{42}$ The doctors who received the online education performed significantly better in a subsequent assessment of their geriatric prescribing knowledge than the doctors who did not receive the education. The intervention was low-cost, reproducible, and user-friendly, as evidenced by the low rate of attrition of doctors in the intervention arm of the trial.

Education techniques that have been proven beneficial should be implemented for prescribing training at both undergraduate and postgraduate level. They should be targeted at those who make most errors, ie, junior doctors, and should focus on locations where errors occur most commonly, ie, hospitals.

In view of the global aging demographic shift and the fact that older multimorbid patients are more vulnerable to prescribing errors, it is imperative that medical students and doctors receive appropriate training in geriatric medicine and geriatric pharmacotherapy, regardless of the career path they 
intend to take. To date, most undergraduate curricula have been lacking in these important areas, although there have been significant concerted efforts recently in Europe ${ }^{43}$ and elsewhere to address this deficiency.

\section{Medication reconciliation}

Most prescribing errors occur at the time of admission to hospital. ${ }^{24}$ For this reason, MR is advisable in all older people at the point of entry to hospital. The four steps of MR are: verification of all drugs, both prescription and nonprescription, currently being taken by the patient; clarification/evaluation of each drug for appropriateness in this particular case; reconciliation of the new complete drug list with the previous drug list, with documentation of all medication changes and reasons for changes; and transmission/communication of the updated accurate drug list to the next care provider.

SHiM (structured history taking of medication use) is a recently devised and validated tool designed to assist doctors and pharmacists to carry out MR in a structured fashion. Its use has been shown to highlight medication discrepancies of potential clinical relevance in approximately $20 \%$ of elderly patients. ${ }^{44}$ Outside the Netherlands (where it originated), SHiM has not been used as a routine tool in clinical practice. Appropriate software to support its deployment may increase its routine use as a means of rapid structured MR.

\section{Pharmacists}

Hospital-based clinical pharmacists can identify prescribing errors through MR. However, after identification of these errors, the next vital step is to advise medical teams on how to rectify these errors. When pharmacists' recommendations are adhered to, patient outcomes improve. ${ }^{43,45}$ Feedback to the prescriber about prescribing errors could potentially reduce the risk of repeated errors, particularly when prescriber knowledge has been shown to be one of the two main characteristics associated with prescriber errors. ${ }^{21}$

The input of clinical pharmacists has also been shown to reduce prescribing errors in acute hospitals, ${ }^{46}$ at time of discharge, ${ }^{47}$ and in intensive care settings. ${ }^{48}$ The number of older patients being admitted to intensive care units has increased, and will likely continue to increase in tandem with global population aging. ${ }^{49}$ It is important that in addressing the problem of prescribing errors, the interventions that show improvement are implemented in the places where older multimorbid adults attend most frequently and have their prescriptions altered. Similar to physicians, clinical pharmacists should have structured training in geriatric medicine and geriatric pharmacotherapy as undergraduates and as postgraduates.

\section{Work environment}

Doctors' work environment has been suggested as a cause of prescribing errors. Insufficient staffing, large workloads, reduced supervision, poor communication, and poor health of workers have all been implicated as contributing factors. ${ }^{22}$

Work environments can be adapted to minimize prescribing errors. Simple changes like minimizing extraneous noise and other distractions in the prescribing environment can reduce prescribing errors. Encouraging all prescribers, regardless of seniority, to check all prescriptions for correct dose, correct formulation, correct mode of delivery, drug-drug and drug-disease interactions, and treatment duration is important in achieving a culture of careful prescribing. Easy access to high-quality formularies (eg, British National Formulary), as well as local, national, and international prescribing guidelines, in particular conditions in paper and online versions, also underpins a cautious prescribing culture. As in all work environments, senior role models are important. Junior prescribers who witness their senior colleagues exercising caution and stringency when prescribing for older people, particularly those with multimorbid illness and associated polypharmacy, are likely to retain good prescribing habits. Sufficient staffing levels with appropriate senior supervision is another key component to the optimal prescribing culture. Prescribing errors, when they occur (particularly those with significant clinical consequences for the older patient), should be reported and discussed with doctors as a group, so that learning opportunities are not missed. Simple changes like the introduction of standardized medication prescription charts have been shown to reduce the frequency of prescribing errors, as well as improve the documentation of ADRs. ${ }^{50}$

\section{The role of information and communication technology}

The impact of computer prescriber order entry (CPOE) system on prescribing errors has been studied extensively in the last 15 years. A recent systematic review concluded that the available evidence is not convincing enough to recommend $\mathrm{CPOE}$ systems as a reliable means of reducing prescribing errors. ${ }^{48}$ The weakness of the evidence in support of $\mathrm{CPOE}$ and prescribing errors relates to small study-sample sizes and suboptimal study design. ${ }^{51}$ Larger studies are needed to investigate the role of $\mathrm{CPOE}$ more thoroughly.

Recent studies have indicated that electronic prescribing (EP) may decrease ambulatory prescribing errors. ${ }^{52,53}$ In the 
hospital setting, EP has been shown to reduce the amount of intervention required by pharmacists, and also to reduce significantly the rate of prescribing errors (from $3.8 \%$ to $2 \%$ ). ${ }^{54}$ These studies relate to prescribing in general rather than prescribing in older people in particular, although there is no reason to believe that EP would not be beneficial in older multimorbid patients with complex polypharmacy.

\section{Prescribing-assessment tools}

There are several elderly-specific prescribing qualityassessment tools in the literature. For the most part, these are broadly divided into implicit and explicit prescribing criteria. The best-known implicit prescribing criteria set is the Medication Appropriateness Index (MAI), first published in $1992 .{ }^{55}$ Hanlon et al, who devised the MAI, proposed that it could be used to assist in recognizing prescribing errors and improving overall prescribing quality in older people. ${ }^{55,56}$ The MAI addresses ten aspects of each drug prescription, as shown in Table 2, aimed at identifying a variety of potential prescribing errors. Several research studies over the last 20 years have shown that the MAI frequently detects potential prescribing errors and predicts adverse health outcomes. ${ }^{57}$ However, as with the SHiM tool, MAI is time-consuming, such that its use has for the most part remained in the realm of research rather than routine clinical practice.

There are several sets of explicit criteria for potential IP in older people in the literature. The Beers criteria were the first explicit criteria, published in $1991,{ }^{58}$ and the fifth iteration of the Beers criteria has been recently published with the endorsement of the American Geriatrics Society. ${ }^{59}$ Explicit criteria sets have been reviewed in detail by $\mathrm{O}^{\prime}$ Connor et $\mathrm{al}^{60}$ with consideration of set strengths and limitations.

In recent years, the STOPP/START criteria have emerged as an alternative to the Beers criteria. STOPP/START criteria originated in Ireland, and were first published in $2008 .{ }^{36}$

Table 2 Medication Appropriateness Index

Is there an indication for the drug?
Is the medication effective for the condition?
Is the dosage correct?
Are the directions correct?
Are the directions practical?
Are there clinically significant drug-drug interactions?
Are there clinically significant drug-disease interactions?
Is there unnecessary duplication with other drugs?
Is the duration of therapy acceptable?
Is this drug the least expensive alternative compared to others of
equal utility?

Is there an indication for the drug?

Is the medication effective for the condition?

Is the dosage correct?

Are the directions correct?

stical?

Are there clinically significant drug-drug interactions?

Are there clinically significant drug-disease interactions?

Is there unnecessary duplication with other drugs?

Is this drug the least expensive alternative compared to others of equal utility?

Clinical Interventions in Aging 2016:1 I

submit your manuscript $\mid$ www.dovepress.com
STOPP criteria are designed to detect and highlight common and preventable potentially inappropriate medications, while the complementary START criteria are focused on potential prescribing omissions, ie, common instances of potentially inappropriate nonprescription of drugs that are potentially highly beneficial to the older person that occur as a result of irrational or ageist reasons. The second iteration of the STOPP/START criteria was published recently, ${ }^{61}$ the total number of criteria increasing from 87 to 114 between version 1 and version 2 . The STOPP/START criteria arose out of perceived deficiencies of the Beers criteria, ${ }^{62}$ and were designed for deployment in routine clinical practice. In the last 5 years, a series of clinical trials has shown tangible clinical benefit when STOPP/START criteria are applied to the medication lists of older people. Gallagher et al showed that STOPP/ START criteria applied at a single time point within 48 hours improve patients' medication appropriateness compared to standard pharmaceutical care, an effect that was maintained to the end of a 6-month post-discharge interval. ${ }^{63}$ A subsequent clinical trial by Frankenthal et $\mathrm{al}^{64}$ showed that routine application of the STOPP/START criteria in older nursinghome residents significantly reduced the average number of daily medications, monthly drug cost, and incidence of falls compared to standard pharmaceutical care. Another recent single-center clinical trial by Dalleur et $\mathrm{al}^{65}$ examined the effect of routine application of the STOPP/START criteria in elderly acutely ill hospitalized patients seen on consultation by the specialist multidisciplinary geriatric medical team. This trial showed that the proportion of patients taking potentially inappropriate drugs at discharge was reduced to approximately half that of the control patients receiving standard pharmaceutical care (19.3\% versus $39.7 \%)$.

In essence, the value of any set of prescribing-appropriateness criteria can be measured by the relevance of the clinical impact that results from routine application of these criteria as an intervention in the target elderly population. At present, STOPP/START are the only set of explicit geriatric prescribing criteria that have shown tangible clinical benefit in older people when tested by clinical trials. However these clinical trials are limited by their smaller scale, as well as their single-center and single-blind designs.

Other prescribing assessment and optimization interventions have been evaluated by RCT, including:

- comprehensive geriatric assessment and management that significantly reduces serious $\mathrm{ADRs}^{66}$

- comprehensive pharmacist intervention that significantly attenuates drug-related hospital readmissions ${ }^{67}$ of acute hospital admission of older people significantly 
- a staff-education program that results in significantly fewer ADEs in geriatric rehabilitation units ${ }^{68}$

- a medication-optimization software system, ie, the Lund Integrated Medicines Management model, which brings about significant reductions in drug-related emergency department attendances and readmissions. ${ }^{69}$

To date, however, none of these prescribing-optimization interventions designed to minimize prescribing errors has come into routine clinical use.

\section{Summary}

The older multimorbid population is expanding globally, and this inevitably means a growth in complex polypharmacy and associated problems of IP and ADRs. Prescribing errors are common in older people with multimorbid illness and polypharmacy, leading to ADRs and events that in turn cause higher levels of morbidity, rehospitalization, and mortality. Screening for and detection of prescribing errors is a growing challenge facing physicians and pharmacists who deal with older multimorbid people who experience polypharmacy. CPOE systems have not been shown conclusively to lessen prescribing errors and associated drug-related morbidity. Making prescribers and pharmacists more "age-attuned" in their prescribing practices is important, and various prescribing-education models exist that can improve prescribing performance.

Medication appropriateness in older people can be measured and assessed using the MAI and the Assessment of Underutilization of Medication tools. However, these are time-consuming, and have not, for the most part, moved beyond the research domain. Potentially inappropriate prescribing, as highlighted by IP criteria sets, such as the Beers criteria and STOPP/START criteria, is a common problem in older people in primary care, in hospital, and in the nursing-home environment. Application of the STOPP/ START criteria to medication lists of older people improves medication appropriateness in hospitalized older patients and reduces polypharmacy, drug costs, and falls incidence in elderly nursing-home residents.

In the future, higher-quality and more efficient computer systems will have a greater role in the routine practice of optimizing pharmacotherapy of older people, particularly those with multimorbid chronic illness and polypharmacy. At present, there are two European Union (EU)-funded multicenter trials in preparation (SENATOR and OPERAM), which will test two similar software systems in their ability to attenuate ADRs and health care costs (SENATOR; EU grant 305930) and rehospitalization and composite health care utilization (OPERAM; EU grant 634238-2) in older multimorbid people recruited from several European clinical sites. The aim of these trials is to build, validate, and test by clinical trial software systems primarily designed around the STOPP/START criteria in the older multimorbid/polypharmacy population, with a view to providing commercially available software for routine clinical use if these trials demonstrate significant and substantial benefit. Even if they do show benefit, their implementation into routine prescribing in older people will require substantial investment in appropriately trained clinical pharmacists and information and communication-technology support. Nevertheless, the trend toward EP and medication surveillance will facilitate the application of prescriptionoptimization software in routine practice.

\section{Disclosure}

Denis O'Mahony and Paul Gallagher with other colleagues devised and validated STOPP/START criteria (versions $1 \& 2$ ). Denis O'Mahony is the co-ordinator of the EU-funded SENATOR project (grant number 305930); Paul Gallagher is a co-principal investigator in SENATOR. Denis O'Mahony is a co-principal investigator on the EU-funded OPERAM project (EU grant number 634238-2). The authors report no other conflicts of interest in this work.

\section{References}

1. United Nations. World Population Ageing 2013. New York: UN; 2013.

2. Centers for Disease Control and Prevention (CDC). Trends in aging United States and worldwide. MMWR Morb Mortal Wkly Rep. 2003; 52(6):101-104, 106.

3. Salive ME. Multimorbidity in older adults. Epidemiol Rev. 2013; 35(1):75-83.

4. Jacobs JM, Maaravi Y, Cohen A, Bursztyn M, Ein-Mor E, Stessman J. Changing profile of health and function from age 70 to 85 years. Gerontology. 2012;58(4):313-321.

5. Steinman MA, Landefeld CS, Rosenthal GE, Berthenthal D, Sen S, Kaboli PJ. Polypharmacy and prescribing quality in older people. $\mathrm{J} \mathrm{Am}$ Geriatr Soc. 2006;54(10):1516-1523.

6. Goldberg RM, Mabee J, Chan L, Wong S. Drug-drug and drug-disease interactions in the ED: analysis of a high-risk population. Am J Emerg Med. 1996;14(5):447-450.

7. Maher RL, Hanlon J, Hajjar ER. Clinical consequences of polypharmacy in elderly. Expert Opin Drug Saf. 2014;13(1):57-65.

8. Stawicki SP, Gerlach AT. Polypharmacy and medication errors: stop, listen, look, and analyze. Opus 12 Sci. 2009;3(1):6-10.

9. Ferner RE, Aronson JK. Clarification of terminology in medication errors: definitions and classification. Drug Saf. 2006;29(11): 1011-1022.

10. Dean B, Barber N, Schachter M. What is a prescribing error? Qual Health Care. 2000;9(4):232-237.

11. Tam VC, Knowles SR, Cornish PL, Fine N, Marchesano R, Etchells EE. Frequency, type and clinical importance of medication history errors at admission to hospital: a systematic review. CMAJ. 2005; 173(5):510-515.

12. Lewis PJ, Dornan T, Taylor D, Tully MP, Wass V, Ashcroft DM. Prevalence, incidence and nature of prescribing errors in hospital inpatients. Drug Saf. 2009;32(5):379-389. 
13. Ashcroft DM, Lewis PJ, Tully MP, et al. Prevalence, nature, severity and risk factors for prescribing errors in hospital inpatients: prospective study in 20 UK hospitals. Drug Saf. 2015;38(9):833-843.

14. Avery T, Barber N, Ghaleb M, et al. Investigating the prevalence and causes of prescribing errors in general practice. 2012. Available from: http://www.gmc-uk.org/about/research/25043.asp. Accessed December 15, 2015.

15. Moore KL, Boscardin WJ, Steinman MA, Schwartz JB. Patterns of chronic co-morbid medical conditions in older residents of U.S. nursing homes: differences between the sexes and across the agespan. $J$ Nutr Health Aging. 2014;18(4):429-436.

16. Barber N, Alldred D, Raynor D, et al. Care homes' use of medicines study: prevalence, causes and potential harm of medication errors in care homes for older people. Qual Saf Health Care. 2009;18(5):341-346.

17. Midlöv P, Bergkvist A, Bondesson A, Eriksson T, Höglund P Medication errors when transferring elderly patients between primary health care and hospital care. Pharm World Sci. 2005;27(2):116-120.

18. CARDI Centre for Ageing Research and Development in Ireland [homepage on the Internet]. Available from: http:/www.cardi.ie/ publications?keys $=\& \& \& \&$ page $=80$. Accessed January 18, 2012.

19. Harris-Kojetin L, Sengupta M, Park-Lee E, Valverde R. Long-Term Care Services in the United States: 2013 Overview. Vital Health Stat 3. 2013;(37):1-107.

20. Hetzel L, Smith A. The 65 years and over population: 2000. 2001 Available from: https://www.census.gov/prod/2001pubs/c2kbr01-10. pdf. Accessed December 15, 2015.

21. Fijn R, Van den Bemt PM, Chow M, De Blaey CJ, De Jong-Van den Berg LT, Brouwers JR. Hospital prescribing errors: epidemiological assessment of predictors. Br J Clin Pharmacol. 2002;53(3):326-331.

22. Dean B, Schachter M, Vincent C, Barber N. Causes of prescribing errors in hospital inpatients: a prospective study. Lancet. 2002;359(9315): 1373-1378.

23. Frank C, Godwin M, Verma S, et al. What drugs are our frail elderly patients taking? Do drugs they take or fail to take put them at increased risk of interactions and inappropriate medication use? Can Fam Physician. 2001;47(6):1198-1204.

24. Dornan T, Ashcroft D, Heathfield H, et al. An in-depth investigation into causes of prescribing errors by foundation trainees in relation to their medical education - EQUIP study. 2009. Available from: http://www.gmc-uk.org/FINAL_Report_prevalence_and_causes_of_ prescribing_errors.pdf_28935150.pdf. Accessed December 15, 2015.

25. Woodhouse KW, Wynne HA. Age-related changes in liver size and hepatic blood flow: the influence on drug metabolism in the elderly. Clin Pharmacokinet. 1988;15(5):287-294.

26. Mangoni AA, Jackson SH. Age-related changes in pharmacokinetics and pharmacodynamics: basic principles and practical applications. Br J Clin Pharmacol. 2004;57(1):6-14.

27. Khan LM. Comparative epidemiology of hospital-acquired adverse drug reactions in adults and children and their impact on cost and hospital stay - a systematic review. Eur J Clin Pharmacol. 2013;69(12): 1985-1996.

28. Pirmohamed M, James S, Meakin S, et al. Adverse drug reactions as cause of admission to hospital: prospective analysis of 18,820 patients. BMJ. 2004;329(7456):15-19.

29. Corsonello A, Pedone C, Corica F, Mussi C, Carbonin P, Antonelli Incalzi R. Concealed renal insufficiency and adverse drug reactions in elderly hospitalized patients. Arch Intern Med. 2005;165(7): 790-795.

30. Bates DW, Boyle DL, Vander Vliet MB, Schneider J, Leape L. Relationship between medication errors and adverse drug events. J Gen Intern Med. 1995;10(4):199-205.

31. Dean B, Schachter M, Vincent C, Barber N. Prescribing errors in hospital inpatients: their incidence and clinical significance. Qual Saf Health Care. 2002;11(4):340-344

32. Heaton A, Webb DJ, Maxwell SR. Undergraduate preparation for prescribing: the views of 2413 UK medical students and recent graduates. Br J Clin Pharmacol. 2008;66(1):128-134.
33. Illing $\mathrm{J}$, Morrow $\mathrm{G}$, Kergon $\mathrm{C}$, et al. How prepared are medical graduates to begin practice? A comparison of three diverse UK medical schools. 2008. Available from: http://www.gmc-uk.org/FINAL_How_ prepared_are_medical_graduates_to_begin_practice_September_08. pdf_29697834.pdf. Accessed December 15, 2015.

34. Ryan C, Ross S, Davey P, et al. Prevalence and causes of prescribing errors: the PRescribing Outcomes for Trainee doctors Engaged in Clinical Training (PROTECT) study. PloS One. 2014;9(1):e79802.

35. Ross S, Loke YK. Do educational interventions improve prescribing by medical students and junior doctors? A systematic review. Br J Clin Pharmacol. 2009;67(6):662-670.

36. Guide to Good Prescribing: a practical manual (WHO/DAP/94.11). TPG De Vries, RH Henning, HV Hogerzeil, DA Fresle. WHO Action Programme on Essential Drugs. WHO, Geneva, 1994. Available from: http://apps.who.int/medicinedocs/pdf/whozip23e/whozip23e.pdf. Accessed January 21, 2016.

37. Gallagher P, Ryan C, Byrne S, Kennedy J, O’Mahony D. STOPP (screening tool of older person's prescriptions) and START (screening tool to alert doctors to right treatment): consensus validation. Int J Clin Pharmacol Ther. 2008;46(2):72-83.

38. Keijsers CJ, van Doorn AB, van Kalles A, et al. Structured pharmaceutical analysis of the systematic tool to reduce inappropriate prescribing is an effective method for final-year medical students to improve polypharmacy skills: a randomized controlled trial. J Am Geriatr Soc. 2014;62(7):1353-1359.

39. Bloom BS. Effects of continuing medical education on improving physician clinical care and patient health: a review of systematic reviews. Int J Technol Assess Health Care. 2005;21(3): $380-385$.

40. Cullinan S, O’Mahony D, Fleming A, Byrne S. A meta-synthesis of potentially inappropriate prescribing in older patients. Drugs Aging. 2014;31(8):631-638.

41. Cullinan S, Fleming A, O'Mahony D, et al. Doctors' perspectives on the barriers to appropriate prescribing in older hospitalized patients: a qualitative study. Br J Clin Pharmacol. 2015;79(5):860-869.

42. Cullinan S. Use of an e-learning educational module to better equip doctors to prescribe for older patients: a randomised controlled trial. (pp 82-98). In: Strategies to prevent potentially inappropriate prescribing and adverse drug reactions in older patients. [PhD thesis] National University of Ireland, University College Cork, 2015.

43. Masud T, Blundell A, Gordon AL, et al. European undergraduate curriculum in geriatric medicine developed using an international modified Delphi technique. Age Ageing. 2014;43(5):695-702.

44. Drenth-van Maanen AC, Spee J, van Hensbergen L, Jansen PA, Egberts TC, van Marum RJ. Structured history taking of medication use reveals iatrogenic harm due to discrepancies in medication histories in hospital and pharmacy records. J Am Geriatr Soc. 2011;59(10):1976-1977.

45. Dale MA, Copeland R, Barton R. Prescribing errors on medical wards and the impact of clinical pharmacists. Int J Pharm Pract. 2003;11(1): 19-24.

46. Tully MP, Buchan IE. Prescribing errors during hospital inpatient care: factors influencing identification by pharmacists. Pharm World Sci. 2009;31(6):682-688.

47. Abdel-Qader DH, Harper L, Cantrill JA, Tully MP. Pharmacists' interventions in prescribing errors at hospital discharge. Drug Saf. 2010;33(11):1027-1044.

48. Klopotowska JE, Kuiper R, van Kan HJ, et al. On-ward participation of a hospital pharmacist in a Dutch intensive care unit reduces prescribing errors and related patient harm: an intervention study. Crit Care. 2010; 14(5):R174.

49. Bagshaw SM, Webb SA, Delaney A, et al. Very old patients admitted to intensive care in Australia and New Zealand: a multi-centre cohort analysis. Crit Care. 2009;13(2):R45.

50. Coombes I, Stowasser D, Reid C, Mitchell C. Impact of a standard medication chart on prescribing errors: a before-and-after audit. Qual Saf Health Care. 2009;18(6):478-485. 
51. Reckmann MH, Westbrook JI, Koh Y, Lo C, Day RO. Does computerized provider order entry reduce prescribing errors for hospital inpatients? A systematic review. J Am Med Inform Assoc. 2009;16(5):613-623.

52. Abramson EL, Barrón Y, Quaresimo J, Kaushal R. Electronic prescribing within an electronic health record reduces ambulatory prescribing errors. Jt Comm J Qual Patient Saf. 2011;37(10):470-478.

53. Kaushal R, Kern LM, Barrón Y, Quaresimo J, Abramson EL. Electronic prescribing improves medication safety in community-based office practices. J Gen Intern Med. 2010;25(6):530-536.

54. Donyai P, O'Grady K, Jacklin A, Barber N, Franklin BD. The effects of electronic prescribing on the quality of prescribing. $\mathrm{Br} \mathrm{J}$ Clin Pharmacol. 2008;65(2):230-237.

55. Hanlon JT, Schmader KE, Samsa GP, et al. A method for assessing drug therapy appropriateness. J Clin Epidemiol. 1992;45(10):1045-1051.

56. Samsa GP, Hanlon JT, Schmader KE, et al. A summated score for the Medication Appropriateness Index: development and assessment of clinimetric properties including content validity. J Clin Epidemiol. 1994;47(8):891-896.

57. Hanlon JT, Schmader KE. The Medication Appropriateness Index at 20: where it started, where it has been, and where it may be going. Drugs Aging. 2013;30(11):893-900.

58. Beers MH, Ouslander JG, Rollingher I, Reuben DB, Brooks J, Beck JC. Explicit criteria for determining inappropriate medication use in nursing home residents. UCLA Division of Geriatric Medicine. Arch Intern Med. 1991;151(9):1825-1832.

59. American Geriatrics Society 2015 Beers Criteria Update Expert Panel. American Geriatrics Society 2015 updated Beers criteria for potentially inappropriate medication use in older adults. J Am Geriatr Soc. 2015;63(11):2227-2246.

60. O'Connor MN, Gallagher P, O’Mahony D. Inappropriate prescribing: criteria, detection and prevention. Drugs Aging. 2012;29(6):437-452.
61. O'Mahony D, O'Sullivan D, Byrne S, O'Connor MN, Ryan C, Gallagher P. STOPP/START criteria for potentially inappropriate prescribing in older people: version 2. Age Ageing. 2015;44(2):213-218.

62. O'Mahony D, Gallagher PF. Inappropriate prescribing in the older population: need for new criteria. Age Ageing. 2008;37(2):138-141.

63. Gallagher PF, O’Connor MN, O’Mahony D. Prevention of potentially inappropriate prescribing for elderly patients: a randomized controlled trial using STOPP/START criteria. Clin Pharmacol Ther. 2011;89(6):845-854.

64. Frankenthal D, Lerman Y, Kalendaryev E, Lerman Y. Intervention with the screening tool of older persons potentially inappropriate prescriptions/screening tool to alert doctors to right treatment criteria in elderly residents of a chronic geriatric facility: a randomized clinical trial. J Am Geriatr Soc. 2014;62(9):1658-1665.

65. Dalleur O, Boland B, Losseau C, et al. Reduction of potentially inappropriate medications using the STOPP criteria in frail older inpatients: a randomised controlled study. Drugs Aging. 2014;31(4):291-298.

66. Schmader KE, Hanlon JT, Pieper CF, et al. Effects of geriatric evaluation and management on adverse drug reactions and suboptimal prescribing in the frail elderly. Am J Med. 2004;116(6):394-401.

67. Gillespie U, Alassaad A, Henrohn D, et al. A comprehensive pharmacist intervention to reduce morbidity in patients 80 years or older: a randomized controlled trial. Arch Intern Med. 2009;169(9):894-900.

68. Trivalle C, Cartier T, Verny C, et al. Identifying and preventing adverse drug events in elderly hospitalised patients: a randomised trial of a program to reduce adverse drug effects. J Nutr Health Aging. 2010; 14(1):57-61.

69. Hellström LM, Bondesson A, Höglund P, et al. Impact of the Lund Integrated Medicines Management (LIMM) model on medication appropriateness and drug-related hospital revisits. Eur J Clin Pharmacol. 2011;67(7):741-752.
Clinical Interventions in Aging

\section{Publish your work in this journal}

Clinical Interventions in Aging is an international, peer-reviewed journal focusing on evidence-based reports on the value or lack thereof of treatments intended to prevent or delay the onset of maladaptive correlates of aging in human beings. This journal is indexed on PubMed Central, MedLine,

\section{Dovepress}

CAS, Scopus and the Elsevier Bibliographic databases. The manuscript management system is completely online and includes a very quick and fair peer-review system, which is all easy to use. Visit http://www.dovepress. com/testimonials.php to read real quotes from published authors. 